\title{
Original Synthesis of Molybdenum Nitrides Using Metal Cluster Compounds as Precursors: Ap- plications in Heterogeneous Catalysis
}

Kevin Guy ${ }^{1,2,3}$, Franck Tessier ${ }^{1}$, Helena Kaper ${ }^{3}$, Fabien Grasset ${ }^{2,4}$, Noée Dumait ${ }^{1}$, Valérie Demange ${ }^{1}$ Mitsuaki Nishio $^{4}$, Yoshitaka Matsushita ${ }^{4}$, Yoshio Matsui ${ }^{4}$, Toshiaki Takei ${ }^{5}$, David Lechevalier ${ }^{2,4}$ Caroline Tardivat $^{3}$, Tetsuo Uchikoshi ${ }^{2,4}$, Naoki Ohashi ${ }^{2,4}$, Stéphane Cordier ${ }^{1}$

${ }^{1}$ Univ. Rennes - CNRS - Institut des Sciences Chimiques de Rennes, UMR 6226, 35000 Rennes, France

${ }^{2}$ CNRS - Saint-Gobain - NIMS, UMI 3629, Laboratory for Innovative Key Materials and Structures (LINK), National Institute for Materials Science, 1-1 Namiki, 305-0044 Tsukuba, Japan

${ }^{3}$ Ceramic Synthesis and Functionalization Laboratory, UMR 3080, CNRS - Saint-Gobain Research Provence, 84306 Cavaillon, France.

${ }^{4}$ Research Center for Functional Materials, National Institute for Materials Science, 305-0044Tsukuba, Japan

${ }^{5}$ Research Center for Materials Nanoarchitectonic, National Institute for Materials Science, 305-0044Tsukuba, Jap an

\section{Corresponding Authors}

\author{
kevin.guy@univ-rennes1.fr \\ franck.tessier@univ-rennes1.fr \\ helena.kaper@saint-gobain.com
}



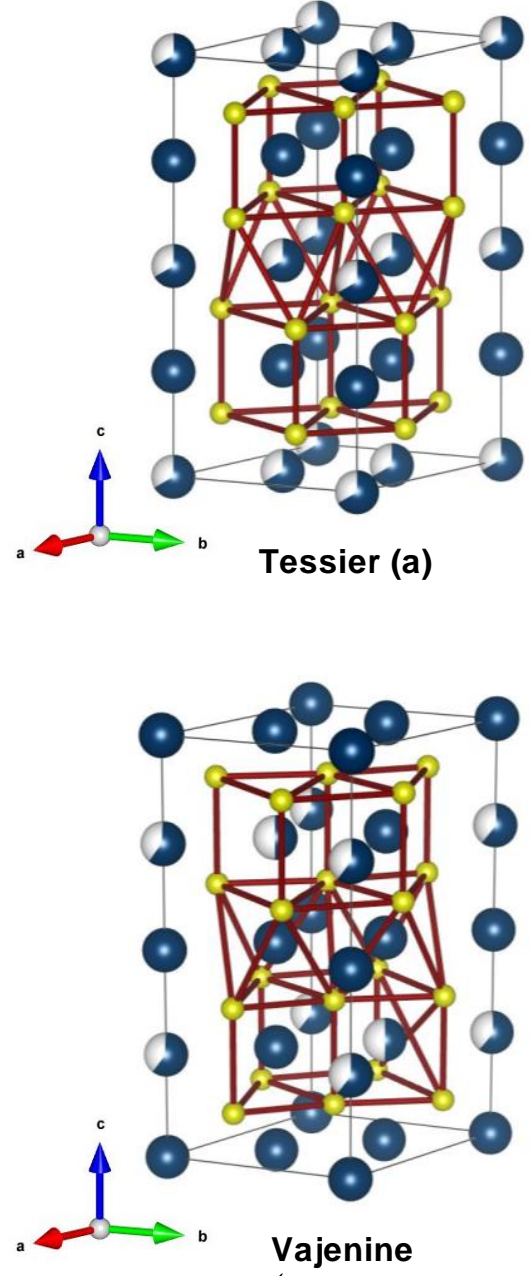
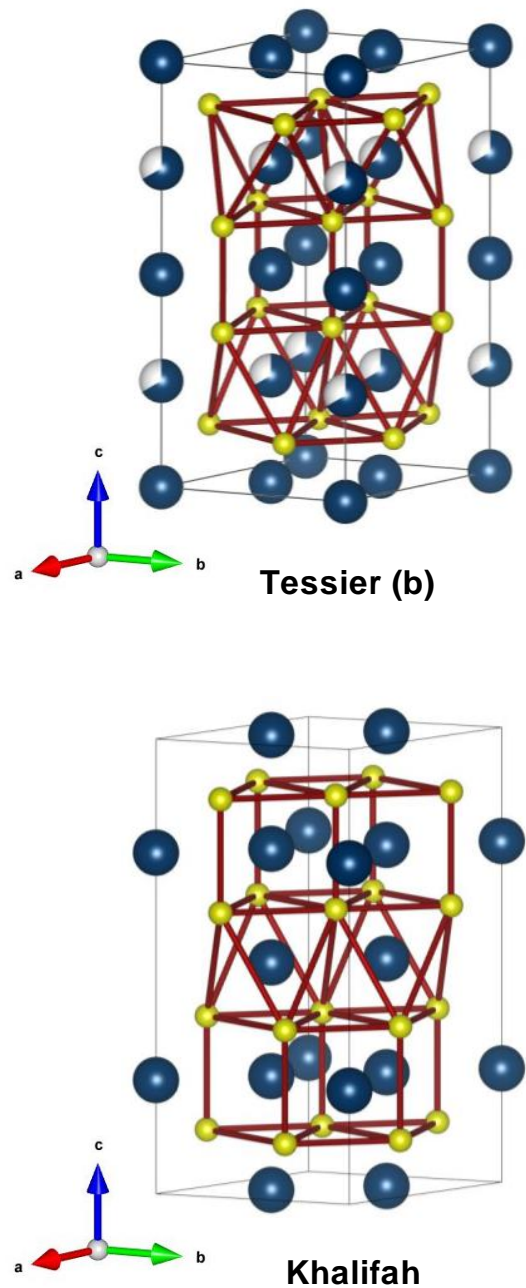

Figure S1. Schemes of the different structures of $\mathrm{Mo}_{5} \mathrm{~N}_{6}$ proposed in the literature by Tessier et al. ${ }^{4}$, Vajenine et al. ${ }^{2}$ and Khalifah et al. ${ }^{6}$. Molybdenum atoms are represented in blue, nitrogen atoms in yellow and vacancies in white.

Tessier (a) Tessier (b) $\quad$ Vajenine (c) $\quad$ Khalifah (d)

$\begin{array}{lcccc}a(\AA) & 4.8960 & 4.8960 & 4.8924 & 4.89688 \\ c(\AA) & 11.0600 & 11.0600 & 11.0643 & 11.0754 \\ V\left(\AA^{3}\right) & 229.5983 & 229.5983 & 229.3498 & 230.0006 \\ \text { Space group } & P 6_{3} / m & P 6_{3} 22 & P 6_{3} / m & P 6_{3} / m c m \\ \text { Mo vacancies site } & \text { Octahedral } & \text { Octahedral } & \text { Prismatic } & \text { Octahedral }\end{array}$

Table S1. Lattice parameters, space group and position of the molybdenum vacancies in the four structures of $\mathrm{Mo}_{5} \mathrm{~N}_{6}$ proposed in the literature. 

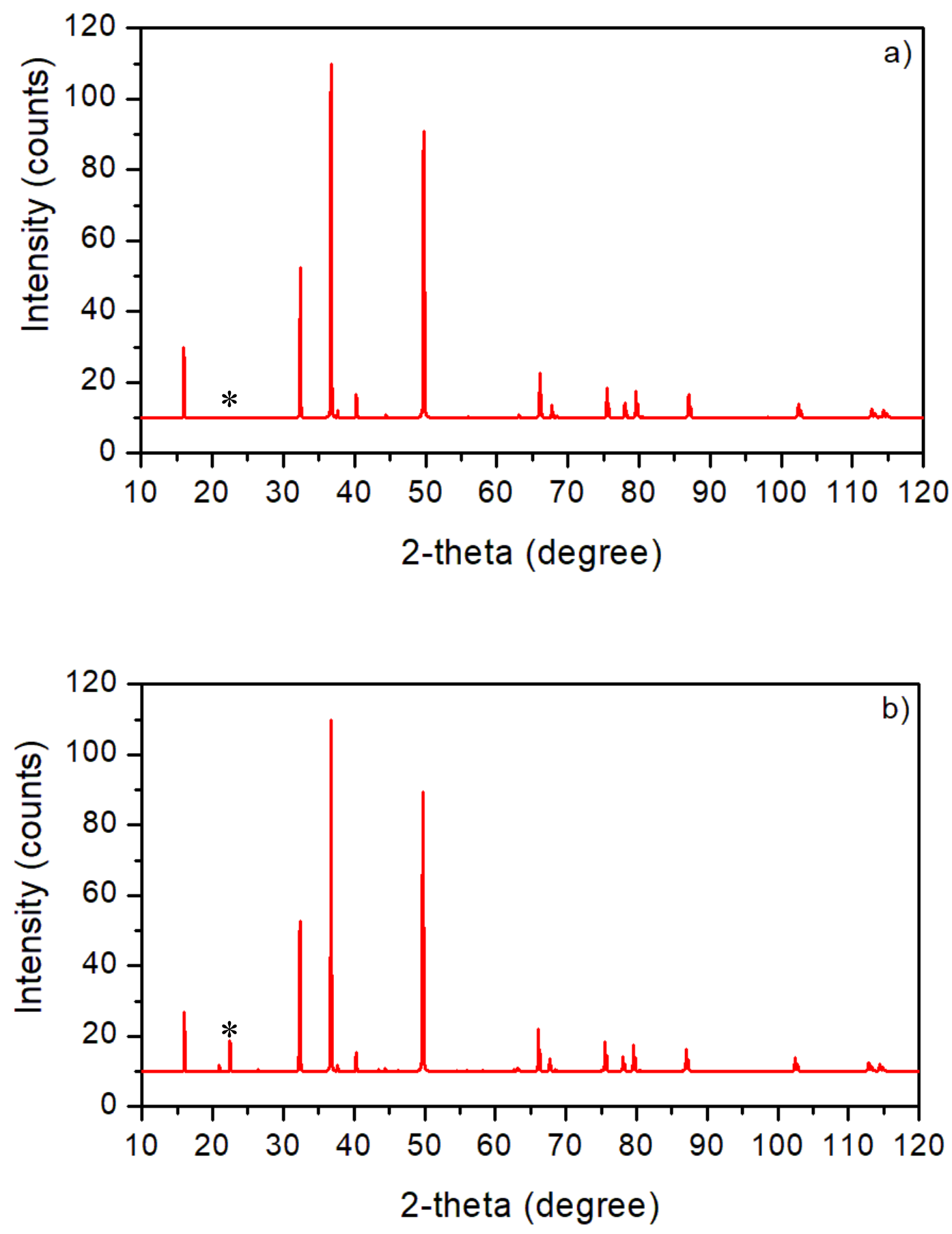

Figure S2. Simulated XRD patterns, obtained with Vesta Software, for $\mathrm{Mo}_{5} \mathrm{~N}_{6}$ according to the model of F. Tessier (a) and the model of V. Vajenine (b). The extinction of the (101) peak is visible on the model of Tessier, annotated by $\left(^{*}\right)$. The two models varies by the position of the molybdenum vacancies. 

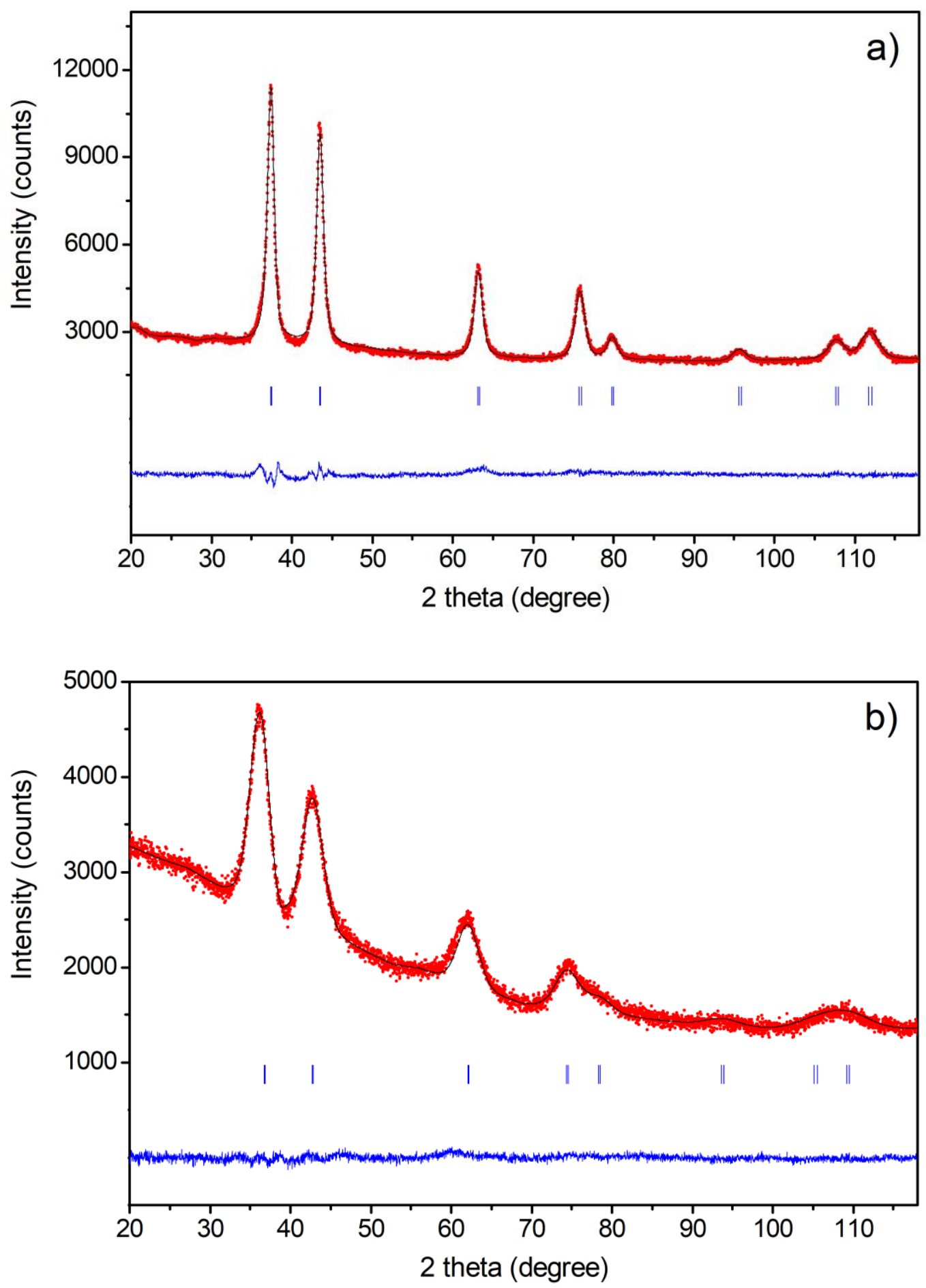

Figure S3.a. Rietveld refinement pattern for $\mathrm{Mo}_{2} \mathrm{~N}-\operatorname{ref}(\mathrm{a})$ and TMB-450 (b): observed (red dotted line), calculated (black line) and difference X-ray powder diffraction profiles from the pattern matching plot obtained with the FullProf Suite Software. The vertical markers correspond to the position of the Bragg reflections. 

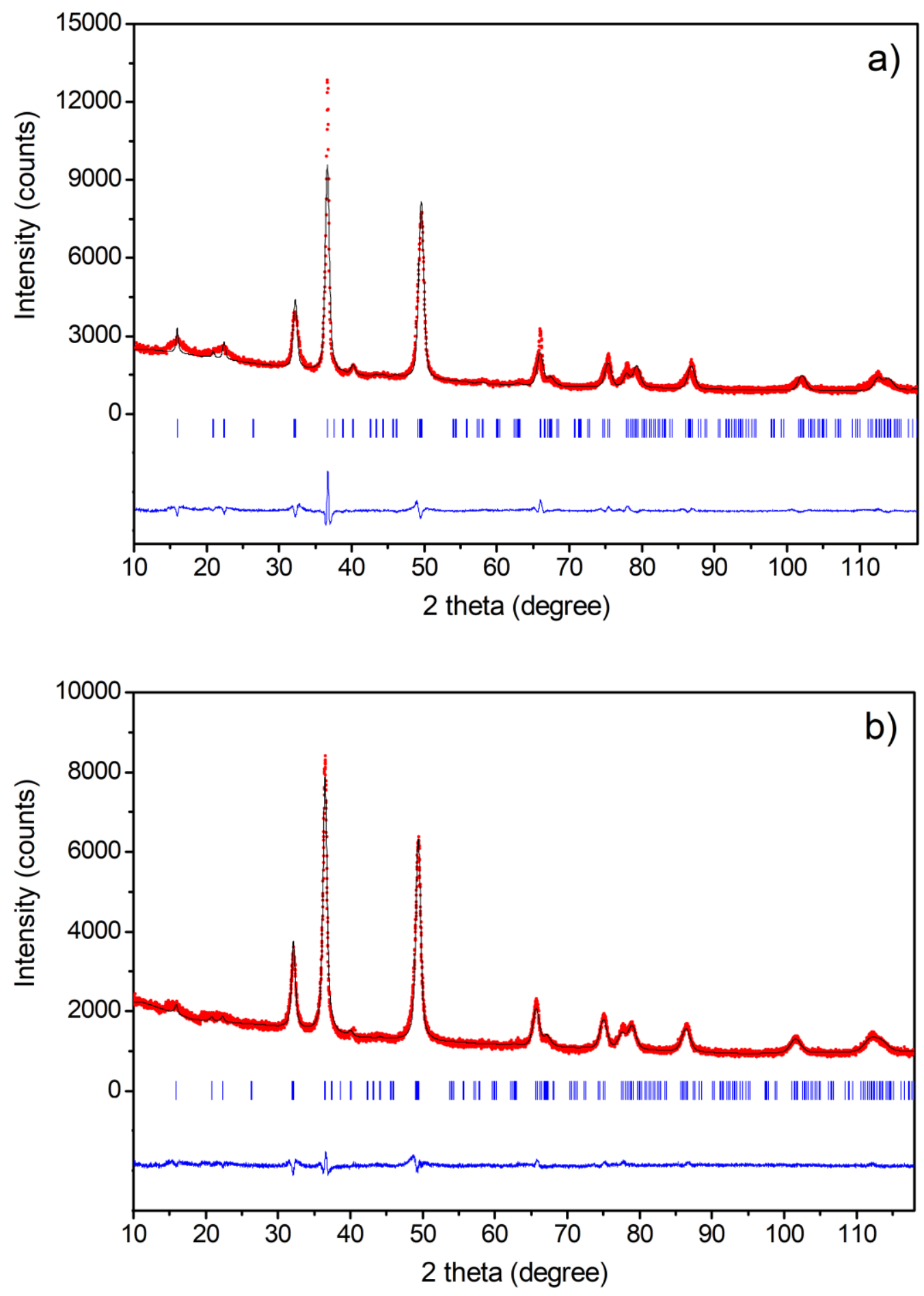

Figure S3.b. Rietveld refinement pattern for $\mathrm{Mo}_{5} \mathrm{~N}_{6}$-ref (a) and TMB-650 (b): observed (red dotted line), calculated (black line) and difference X-ray powder diffraction profiles from the pattern matching plot obtained with the FullProf Suite Software. The vertical markers correspond to the position of the Bragg reflections. 
Table S2. Details of the Rietveld refinements and crystallites size for $\mathrm{Mo}_{2} \mathrm{~N}$-ref, TMB-450, $\mathrm{Mo}_{5} \mathrm{~N}_{6}$-ref and TMB-650 obtained with the FullProf Suite Software. Function no. 7 is used, and the parameters U, X, Y and Gausize are refined for each sample, giving an isotropic model concerning the crystallites size and the strain.

$\mathrm{Mo}_{2} \mathrm{~N}$-ref

Lattice

$\begin{aligned} & a(\AA) \\ & c(\AA)\end{aligned}$
$V\left(\AA^{3}\right)$
Space group
$\quad$ Refinement
N0. Diffraction peaks (Ka/K $\beta)$
N0. Background points
N0. Refined parameters
N0. atoms
Rp (\%)
Rwp (\%)
Rexp (\%)
$X^{2}$

Microstructure

Crystallites size $(\mathrm{nm})$

$\varepsilon$
TMB-450

$4.2147(9)$

74.87(3)

F $m-3 m$
$\mathrm{Mo}_{5} \mathrm{~N}_{6}$-ref

4.90498(3)

$11.1080(7)$

231.41(2)

$P 6_{3} / \mathrm{m}$

$312 / 2$

12

15

6

5.81

7.86

2.52

9.73

1.73
2.89

2.19
20.7(1)

15.4(1)

$0.0367(3)$

TMB-650

4.9236(2)

11.1456(4)

233.99(2)

$P 6_{3} / \mathrm{m}$

$338 / 2$

10

15

6

3.57

4.57

2.65

2.99

$0.24(6)$

$0.047(5)$ 

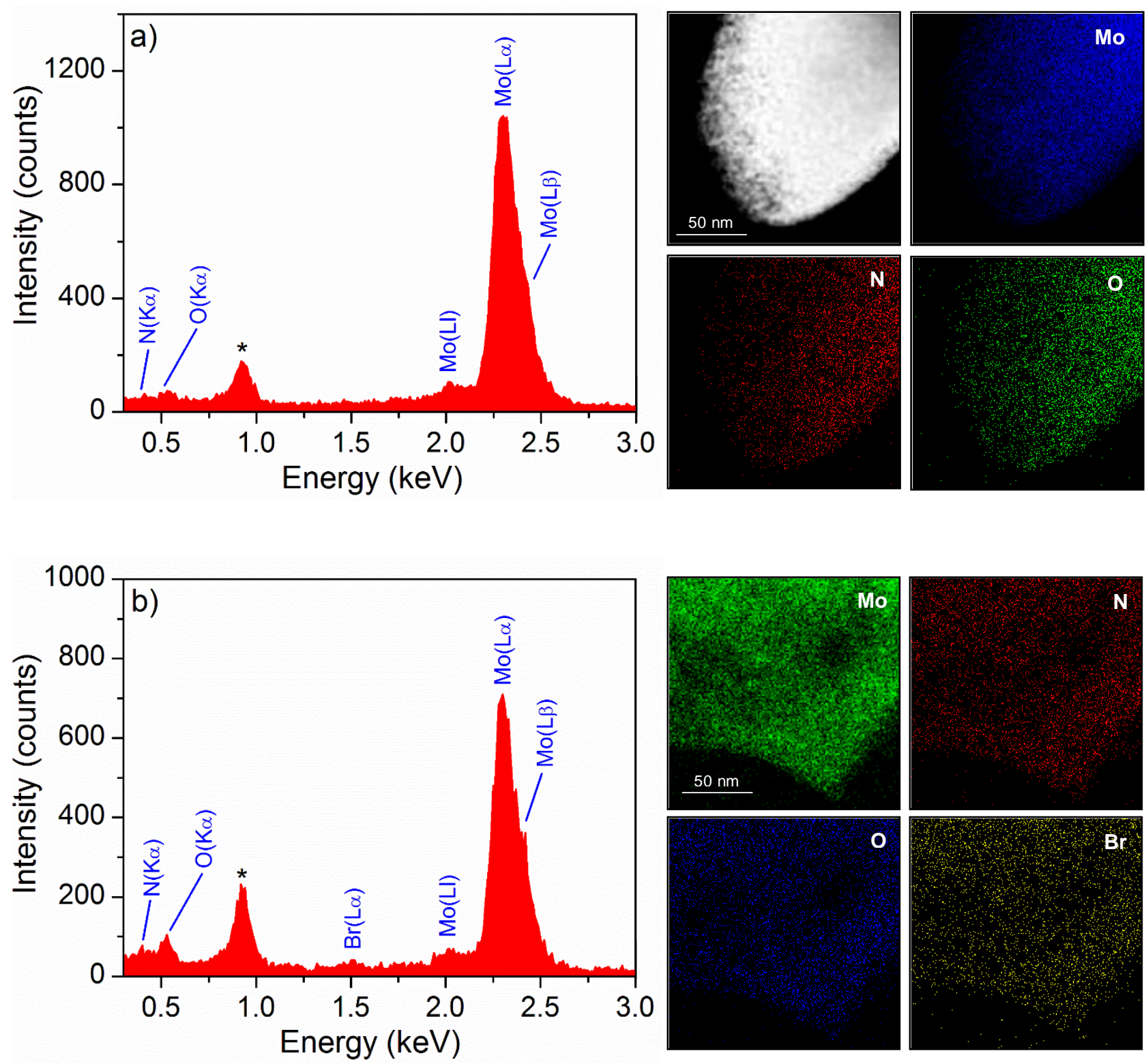

Figure S4.a. EDS-TEM spectra and mapping for molybdenum, nitrogen, oxygen and bromine for $\mathrm{Mo}_{2} \mathrm{~N}$ samples: $\mathrm{Mo}_{2} \mathrm{~N}$-ref (a) and TMB-450 (b). Peaks identified as $\left(^{*}\right)$ correspond to the $\mathrm{Cu}$ grid used for TEM analyses. 

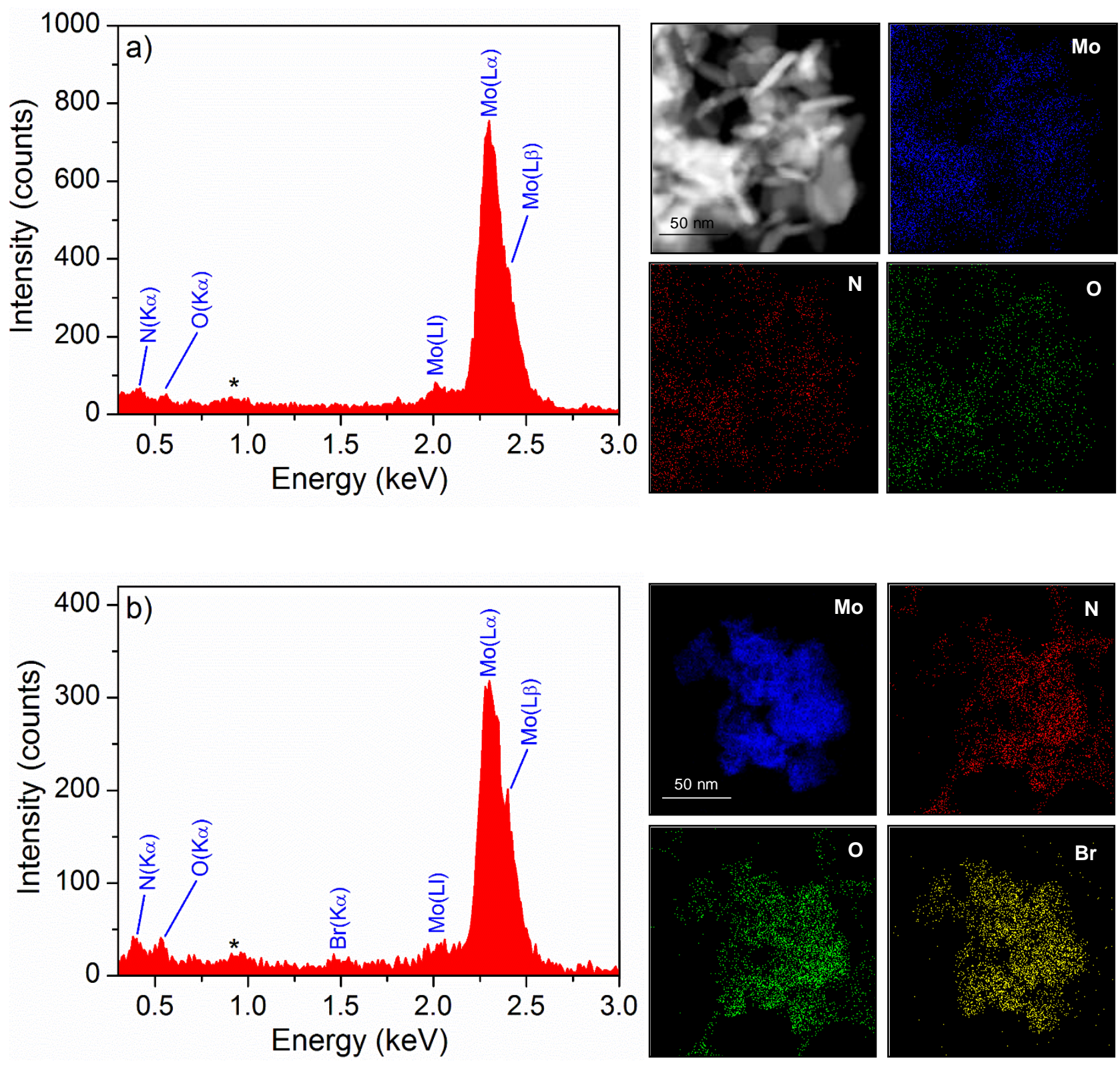

Figure S4.b. EDS-TEM spectra and mapping for molybdenum, nitrogen, oxygen and bromine for $\mathrm{Mo}_{5} \mathrm{~N}_{6}$ samples: $\mathrm{Mo}_{5} \mathrm{~N}_{6}$-ref (a) and TMB-500 (b). Peaks identified as $\left({ }^{*}\right)$ correspond to the $\mathrm{Cu}$ grid used for TEM analyses. 
a)
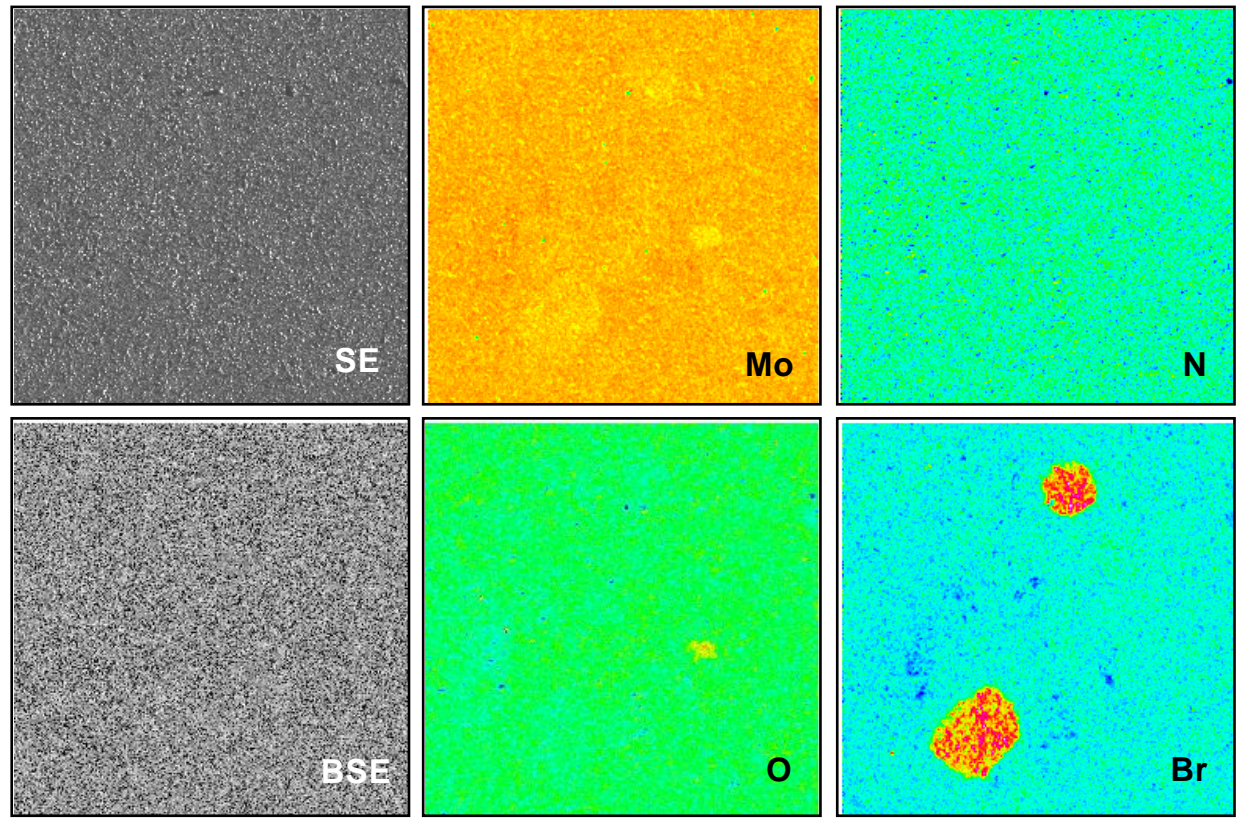

0
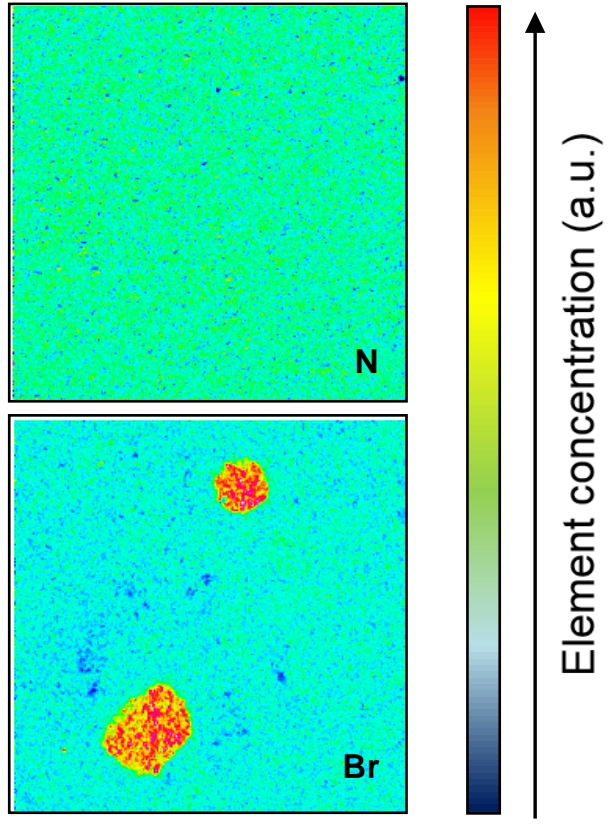

b)
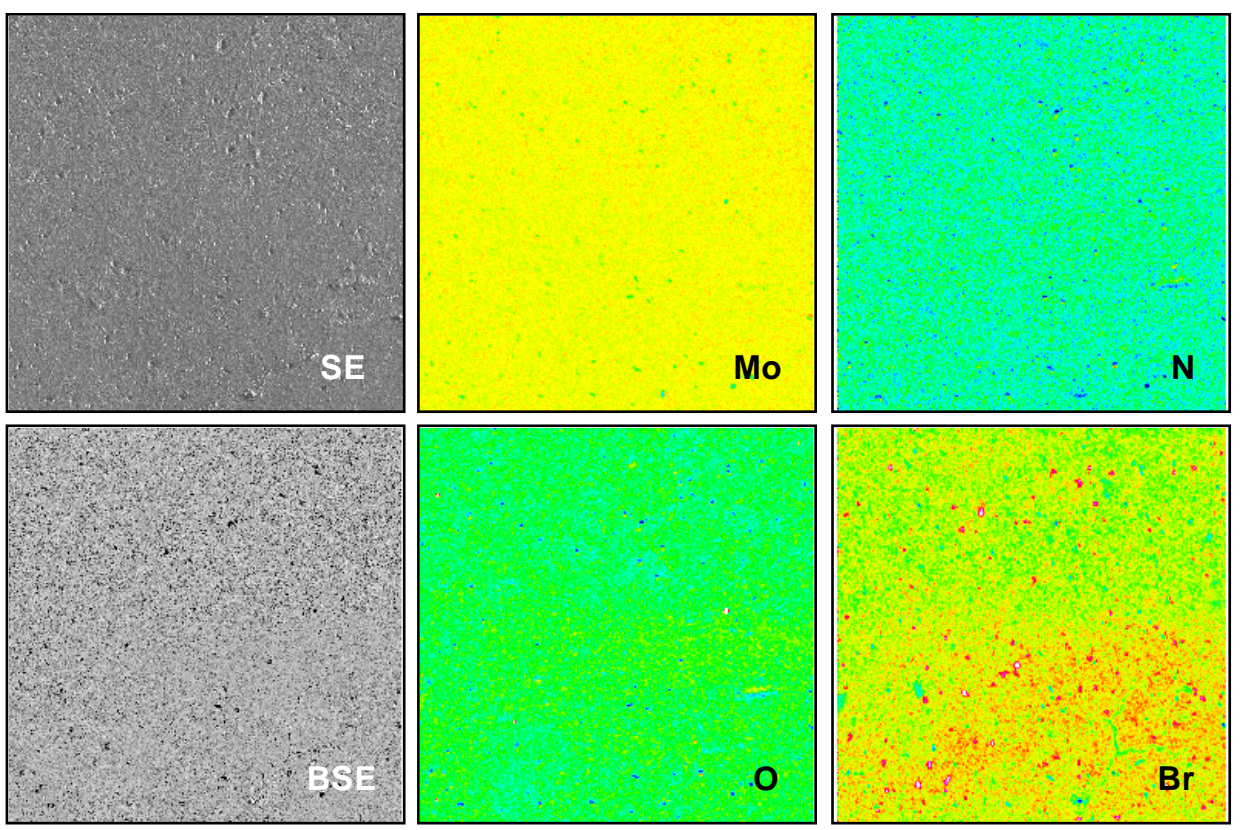

Figure S5. WDS-EPMA mapping for molybdenum, nitrogen, oxygen and bromine on TMB-500 (a) and TMB-450 (b). SE corresponds to secondary electron observations and BSE to backscatte ring electron observations. 


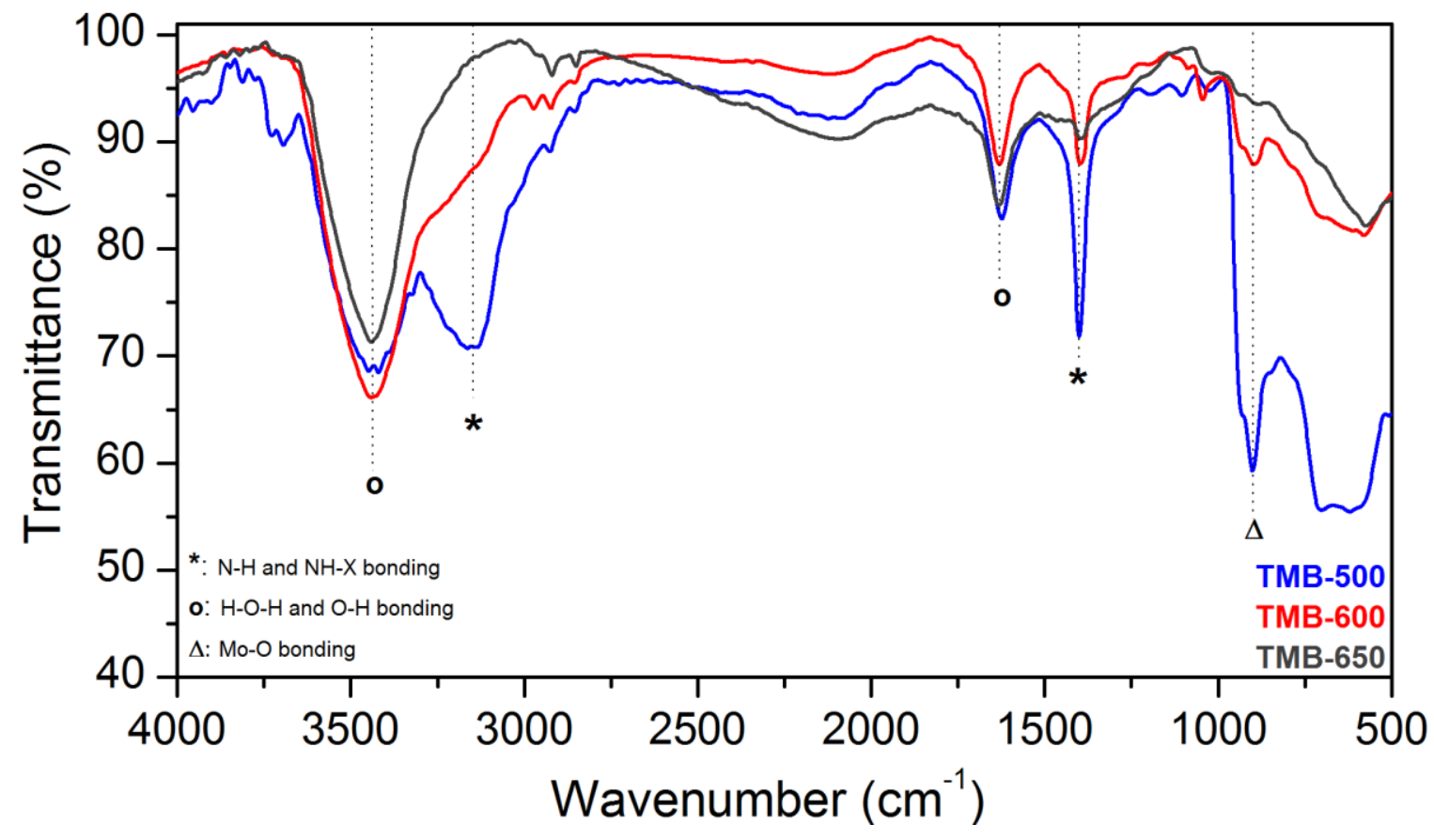

Figure S6. Fourier transformed infrared spectra for TMB-500, TMB-600 and TMB-650 shows the impact of the ammonolysis temperature on the presence of Mo-O, N-H and NH-X peaks. Increasing the ammonolysis temperature up to $650^{\circ} \mathrm{C}$ allows to prevent the formation of $\mathrm{NH}_{4} \mathrm{Br}$, in good accordance with the results obtained by WDS-EPMA (Figure 4 and Figure S2). 

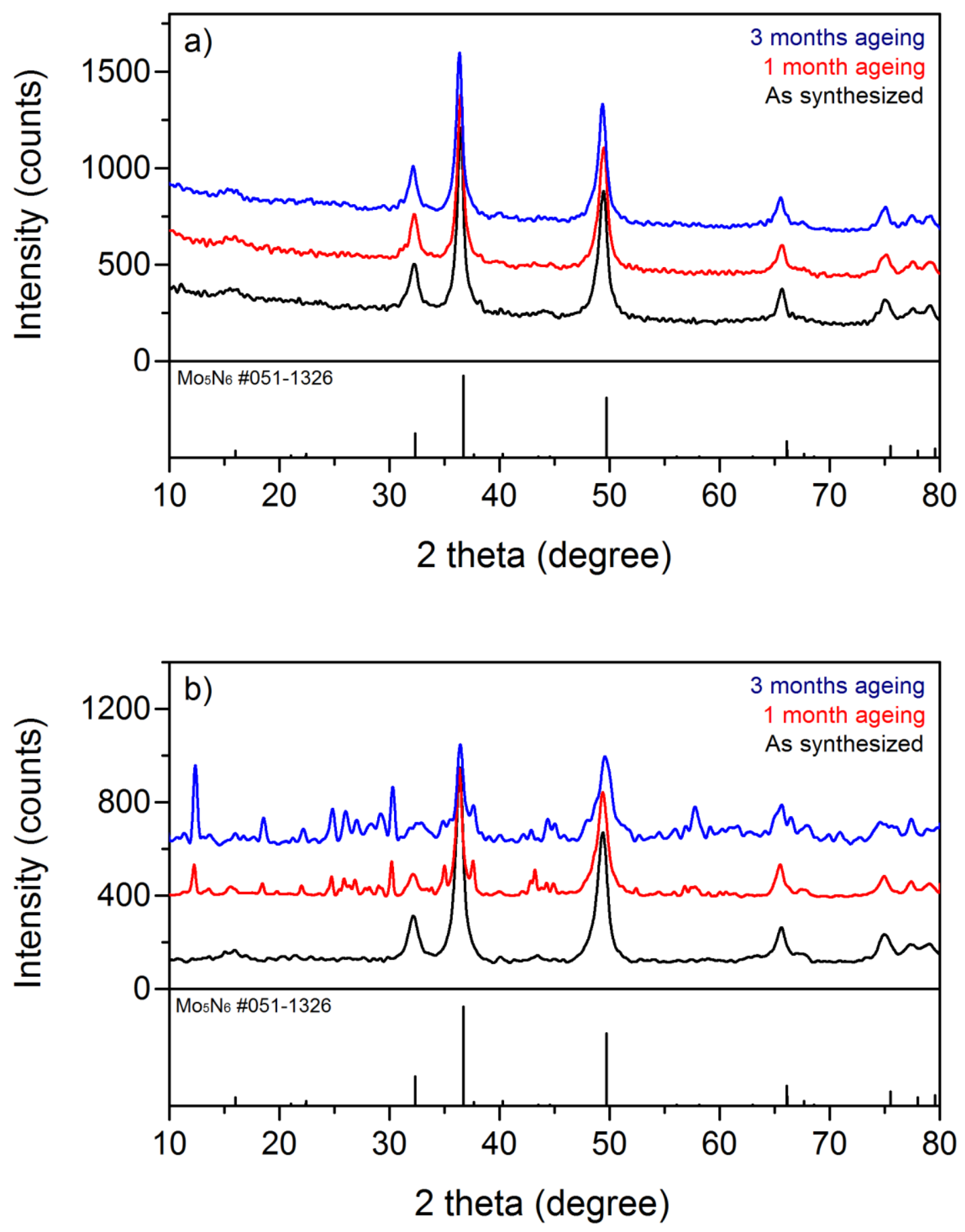

Figure S7. XRD patterns of TMB-650 (a) and TMB-500 (b) as synthesized, and after 1 month and three months of ageing under ambient conditions. Additional peaks observed for TMB-500 after one month and three months of ageing corresponds to the degradation of $\mathrm{Mo}_{5} \mathrm{~N}_{6}$ into $\mathrm{MoO}_{2}$ and $\mathrm{MoO} 3$. This is due to the presence of $\mathrm{NH}_{4} \mathrm{Br}$ on TMB-500, modifying the basicity of the surface. 

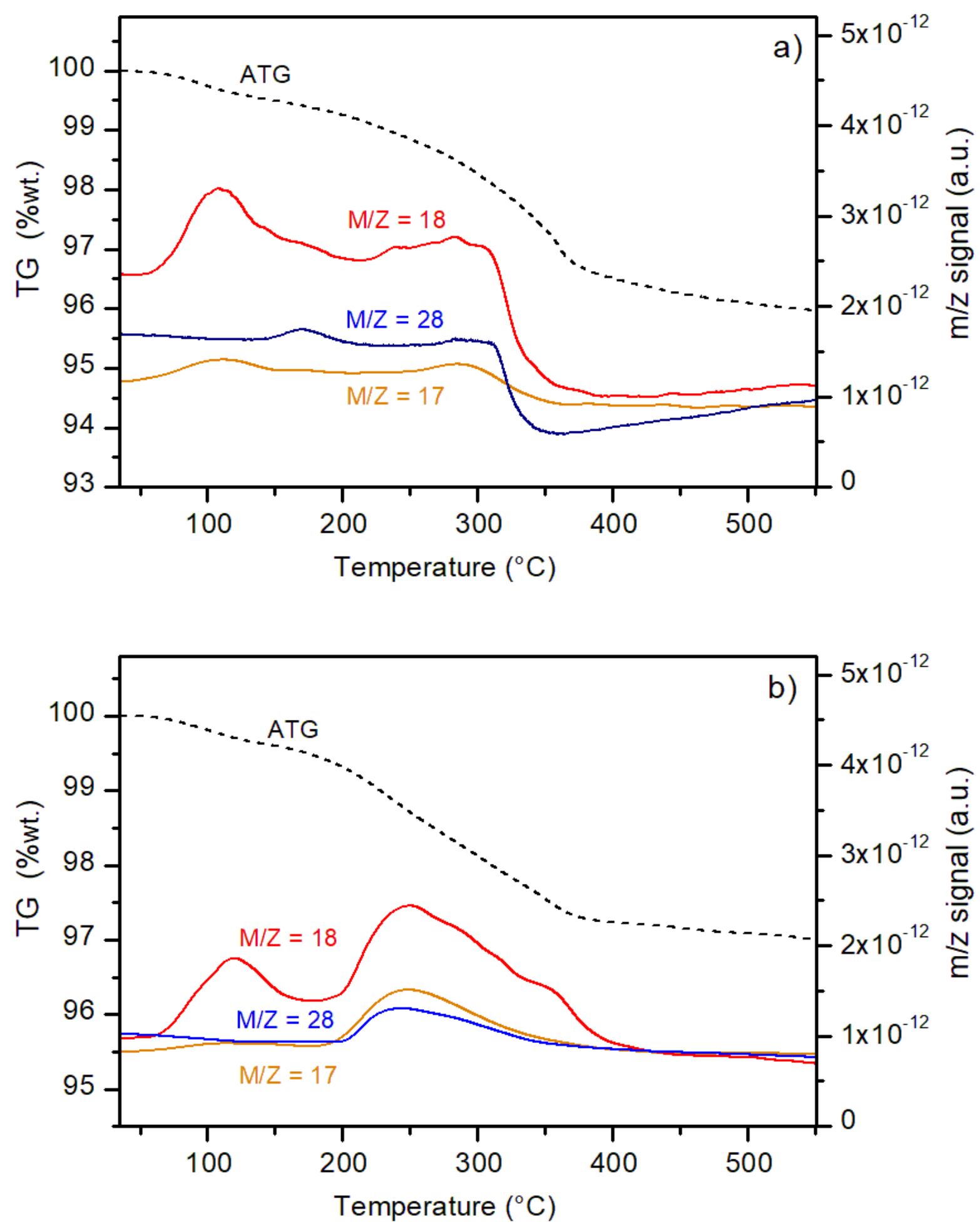

Figure S8. ATG curves (black dotted line) coupled with mass spectroscopy. $\mathrm{m} / \mathrm{z}=17$ (orange line), 18 (red line) and 28 (blue line) are represented. Samples $\mathrm{Mo}_{5} \mathrm{~N}_{6}$-ref (a) and TMB-650 are presented (b). 

Precursors for Heterogeneous Catalysis Applications"

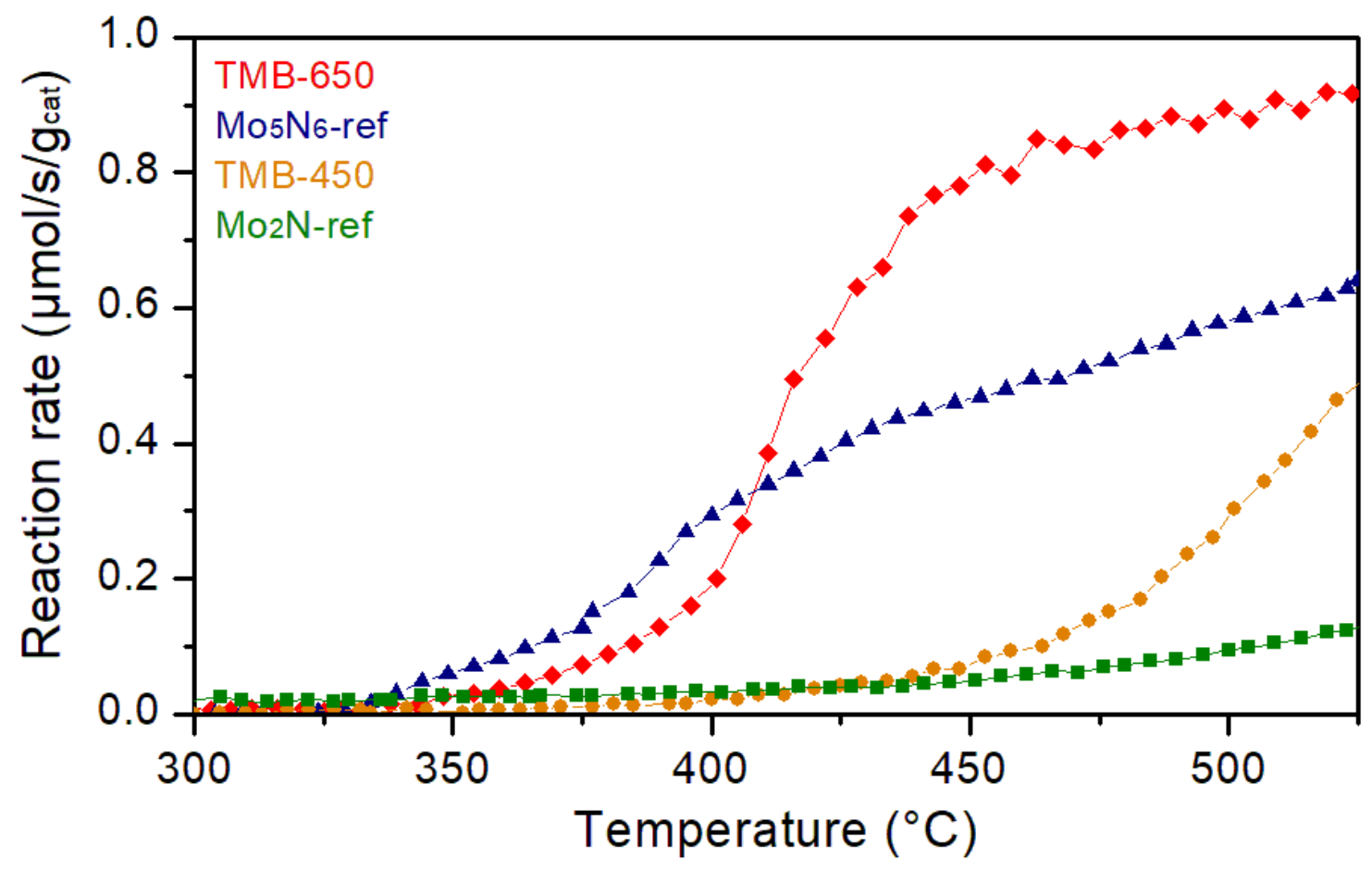

Figure S9. Catalytic performance of the catalysts for the WGSR given in terms of normalized reaction rate, in function of the weight of $\mathrm{Mo}_{5} \mathrm{~N}_{6}$. Light-off curves of TMB-650, $\mathrm{Mo}_{5} \mathrm{~N}_{6}$-ref, TMB-450 and $\mathrm{Mo}_{2} \mathrm{~N}$-ref. 

Precursors for Heterogeneous Catalysis Applications"

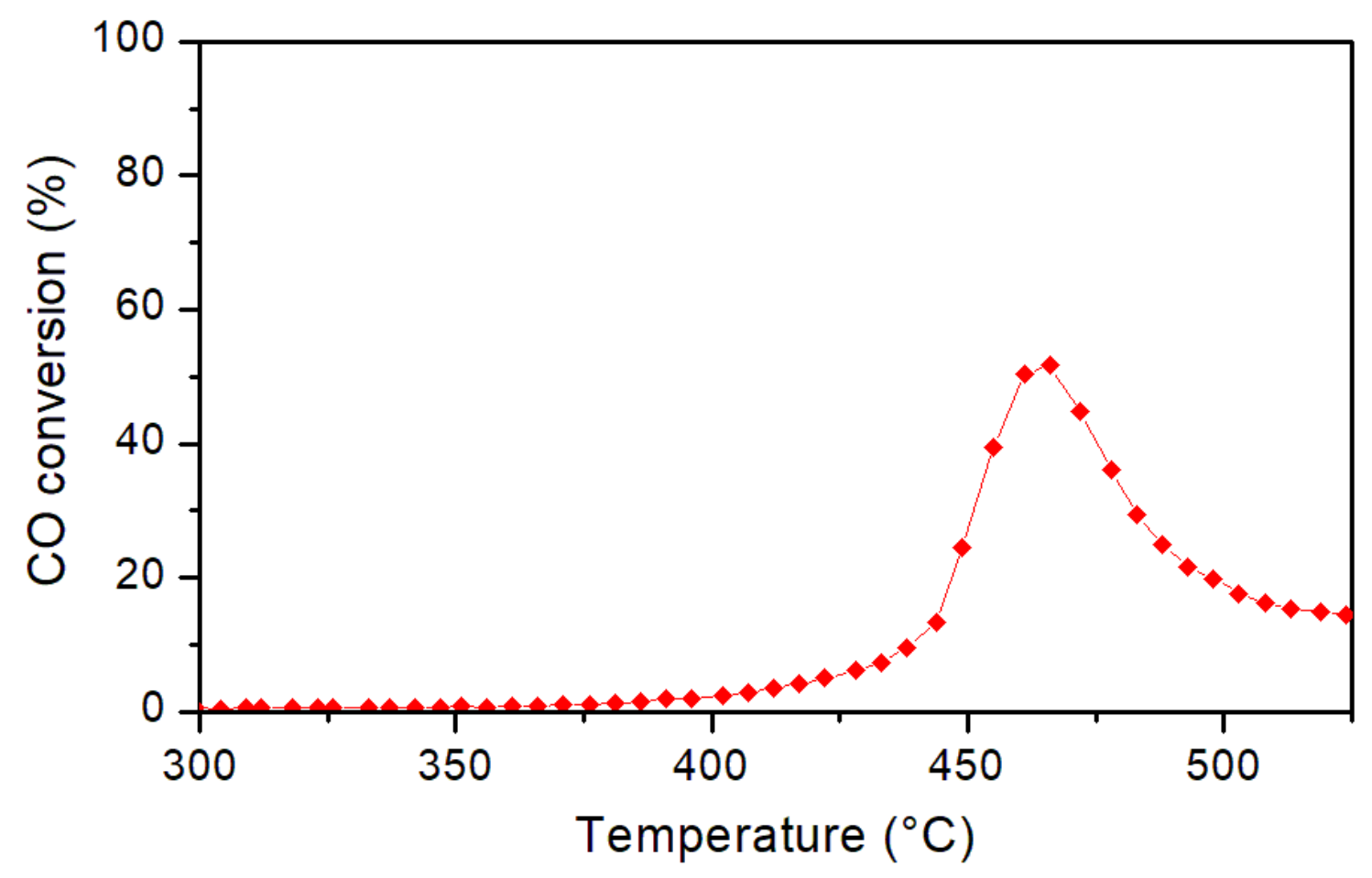

Figure S10. $\mathrm{CO}$ to $\mathrm{CO}_{2}$ conversion for TMB-650 in function of the temperature, in presence of $\mathrm{CO}$ only. 

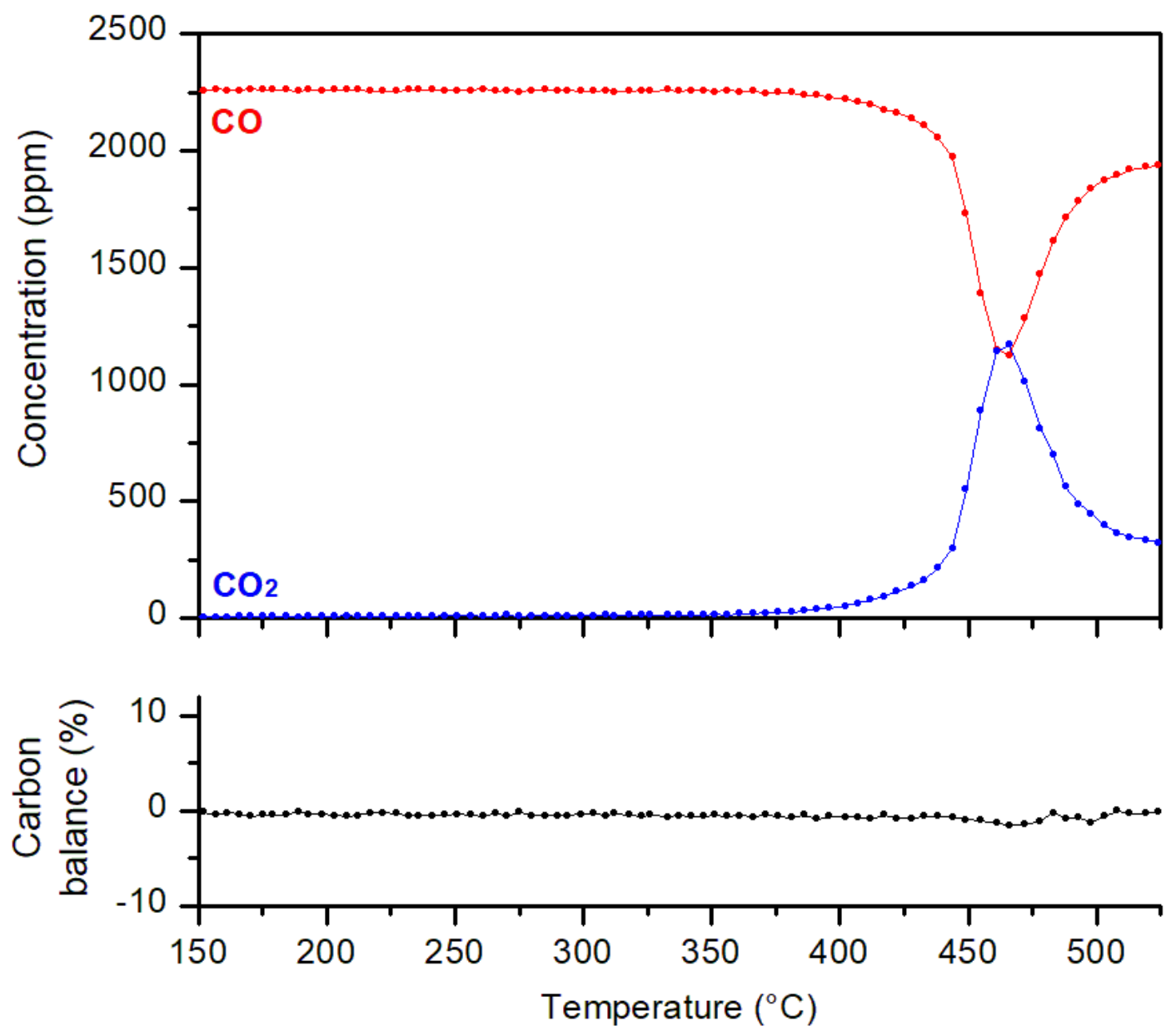

Figure S11. Product profile of TMB-650 during the catalytic test under CO only. Red line corresponds to the concentration of CO and blue line to $\mathrm{CO}_{2}$ (in ppm), in function of the temperature. Black line shows the carbon balance as a function of the temperature (CO consumed minus $\mathrm{CO}_{2}$ formed, divided by initial $\mathrm{CO}$ concentration). 

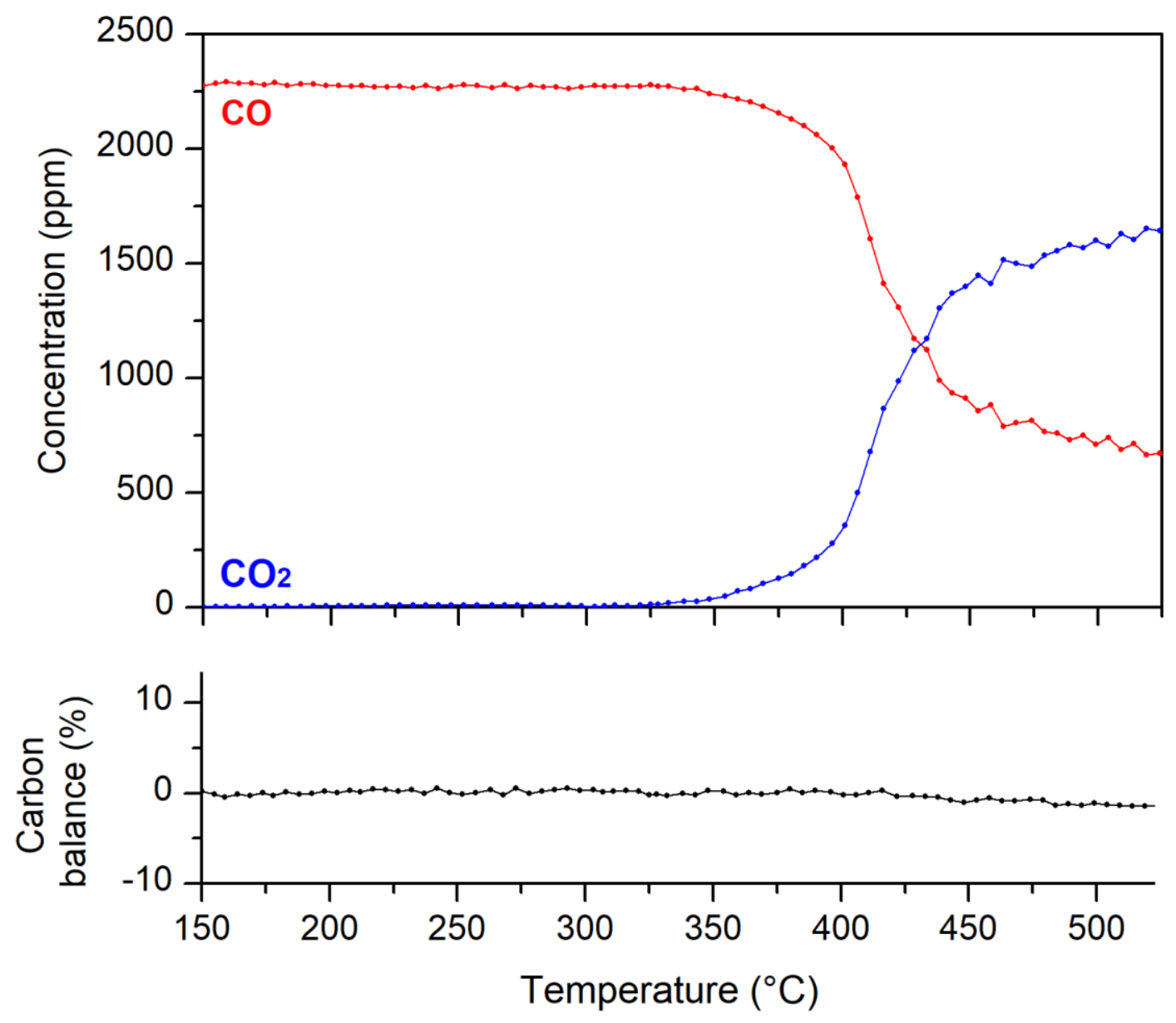

Figure S12. Product profile of TMB-650 during the WGSR first light-off. Red line corresponds to the concentration of CO and blue line to $\mathrm{CO}_{2}$ (in ppm), in function of the temperature. Black line shows the carbon balance as a function of the temperature (CO consumed minus $\mathrm{CO}_{2}$ formed, divided by initial $\mathrm{CO}$ concentration). 

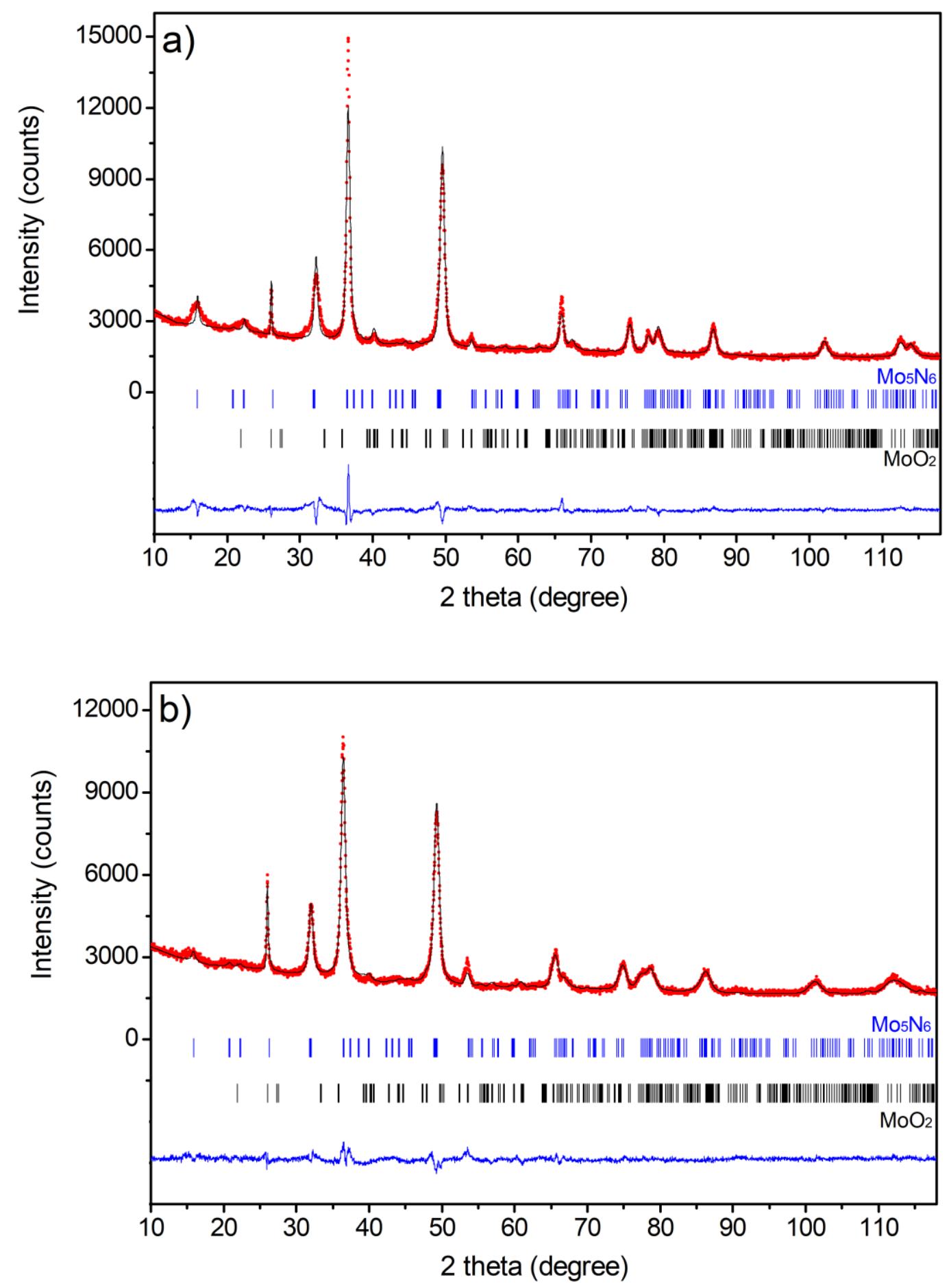

Figure S13. Rietveld refinement pattern for $\mathrm{Mo}_{5} \mathrm{~N}_{6}$-ref (a) and TMB-650 (b) after 3 WGSR consecutive light-off: observed (red dotted line), calculated (black line) and difference X-ray powder diffraction profiles from the pattern matching plot obtained with the FullProf Suite Software. The vertical markers correspond to the position of the Bragg reflections for $\mathrm{Mo}_{5} \mathrm{~N}_{6}(\mathrm{blue})$ and $\mathrm{MoO}_{2}(\mathrm{black})$. 
Table S3. Details of the Rietveld refinements and crystallites size for $\mathrm{Mo}_{5} \mathrm{~N}_{6}$-ref and TMB-650 after 3 WGSR consecutive light-off obtained with the FullProf Suite Software. Function no. 7 is used, and the parameters U, X, Y and Gausize are refined for each sample, giving an isotropic model concerning the crystallites size and the strain.

$\mathrm{Mo}_{5} \mathrm{~N}_{6}$-ref

\section{Lattice $\left(\mathrm{Mo}_{5} \mathrm{~N}_{6}\right)$}

$a(\AA ̊)$

$c(\AA)$

$\mathrm{V}\left(\AA^{3}\right)$

Space group

Fraction (\%wt.)

Lattice $\left(\mathrm{MoO}_{2}\right)$

$a(\AA)$
$b(\AA)$
$c(\AA)$
$\beta\left({ }^{\circ}\right)$
$V\left(\AA^{3}\right)$
Space group
Fraction (\%wt.)

\section{Refinement}

NO. Diffraction peaks $(K \alpha / K \beta)$

NO. Background points

NO. Refined parameters

$\mathrm{Rp}(\%)$

Rwp (\%)

$\operatorname{Rexp}(\%)$

$x^{2}$

\section{Microstructure}

Crystallites size (nm)

Maximum strain

$\begin{array}{cc}4.90558(2) & 4.93155(2) \\ 11.10984(6) & 11.17950(6) \\ 231.54(2) & 235.46(2) \\ P 6_{3} / m & P 6_{3} / m \\ 94(3) \% & 85(1) \%\end{array}$

4.366(2)

4.603(2)

$5.585(2)$

$5.371(1)$

4.904(2)

$5.042(2)$

118.19(1)

118.11(3)

105.41(8)

109.96(7)

$P 21 / C$

$P 21 / C$

$6(3) \%$

$15(1) \%$

$351 / 2$

$321 / 2$

15

13

23

23

4.33

3.02

5.87

3.88

2.10

2.05

7.79

3.59

15.3(1)

12.7(1)

$0.0265(1)$ 


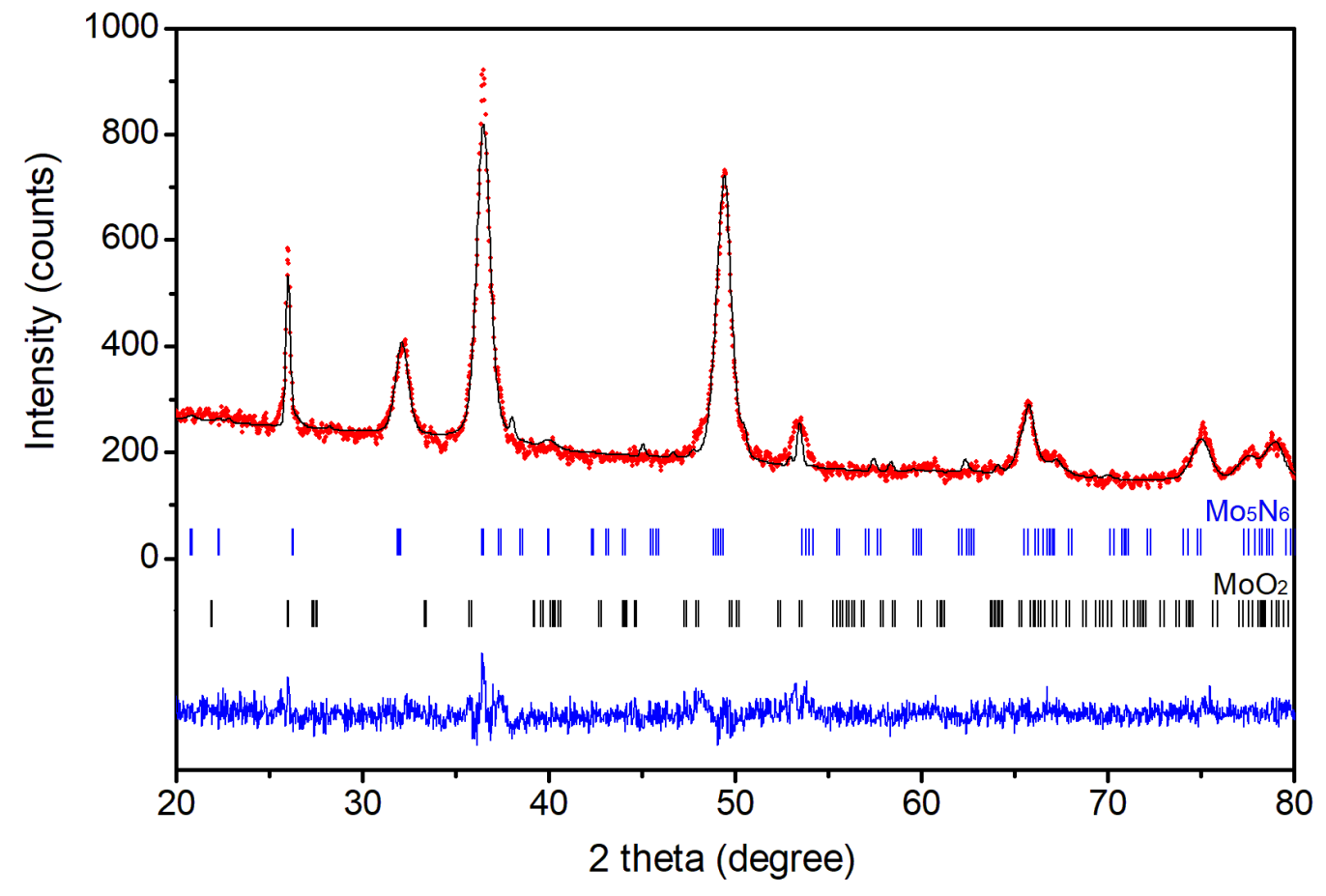

Figure S14. Rietveld refinement pattern for TMB-650 after hydrothermal test: observed (red dotted line), calculated (black line) and difference X-ray powder diffraction profiles from the pattern matching plot obtained with the FullProf Suite Software. The vertical markers correspond to the position of the Bragg reflections for $\mathrm{Mo}_{5} \mathrm{~N}_{6}$ (blue) and $\mathrm{MoO}_{2}$ (black). 
Table S4. Details of the Rietveld refinements for TMB-650 after hydrothermal test obtained with the FullProf Suite Software, using the function no. 7 .

TMB-650

\begin{tabular}{|c|c|}
\hline \multicolumn{2}{|c|}{ Lattice $\left(\mathrm{Mo}_{5} \mathrm{~N}_{6}\right)$} \\
\hline$a(\AA)$ & $4.9250(7)$ \\
\hline$c(\AA)$ & $11.147(2)$ \\
\hline$V\left(\AA^{3}\right)$ & $234.17(6)$ \\
\hline Space group & $P 6_{3} / m$ \\
\hline Fraction (\%wt.) & $87(3) \%$ \\
\hline \multicolumn{2}{|c|}{ Lattice $\left(\mathrm{MoO}_{2}\right)$} \\
\hline$a(\AA)$ & $4.308(1)$ \\
\hline$b(\AA ̊)$ & $5.663(2)$ \\
\hline$c(\AA)$ & $4.764(2)$ \\
\hline$\beta\left(^{\circ}\right)$ & $115.34(6)$ \\
\hline$V\left(\AA^{3}\right)$ & $105.06(6)$ \\
\hline Space group & $P 2_{1} / C$ \\
\hline Fraction (\%wt.) & $13(3) \%$ \\
\hline \multicolumn{2}{|c|}{ Refinement } \\
\hline NO. Diffraction peaks $(\mathrm{K \alpha} / \mathrm{K} \beta)$ & $328 / 2$ \\
\hline N0. Background points & 9 \\
\hline NO. Refined parameters & 23 \\
\hline $\operatorname{Rp}(\%)$ & 6.84 \\
\hline Rwp (\%) & 8.73 \\
\hline $\operatorname{Rexp}(\%)$ & 6.40 \\
\hline$x^{2}$ & 1.86 \\
\hline
\end{tabular}




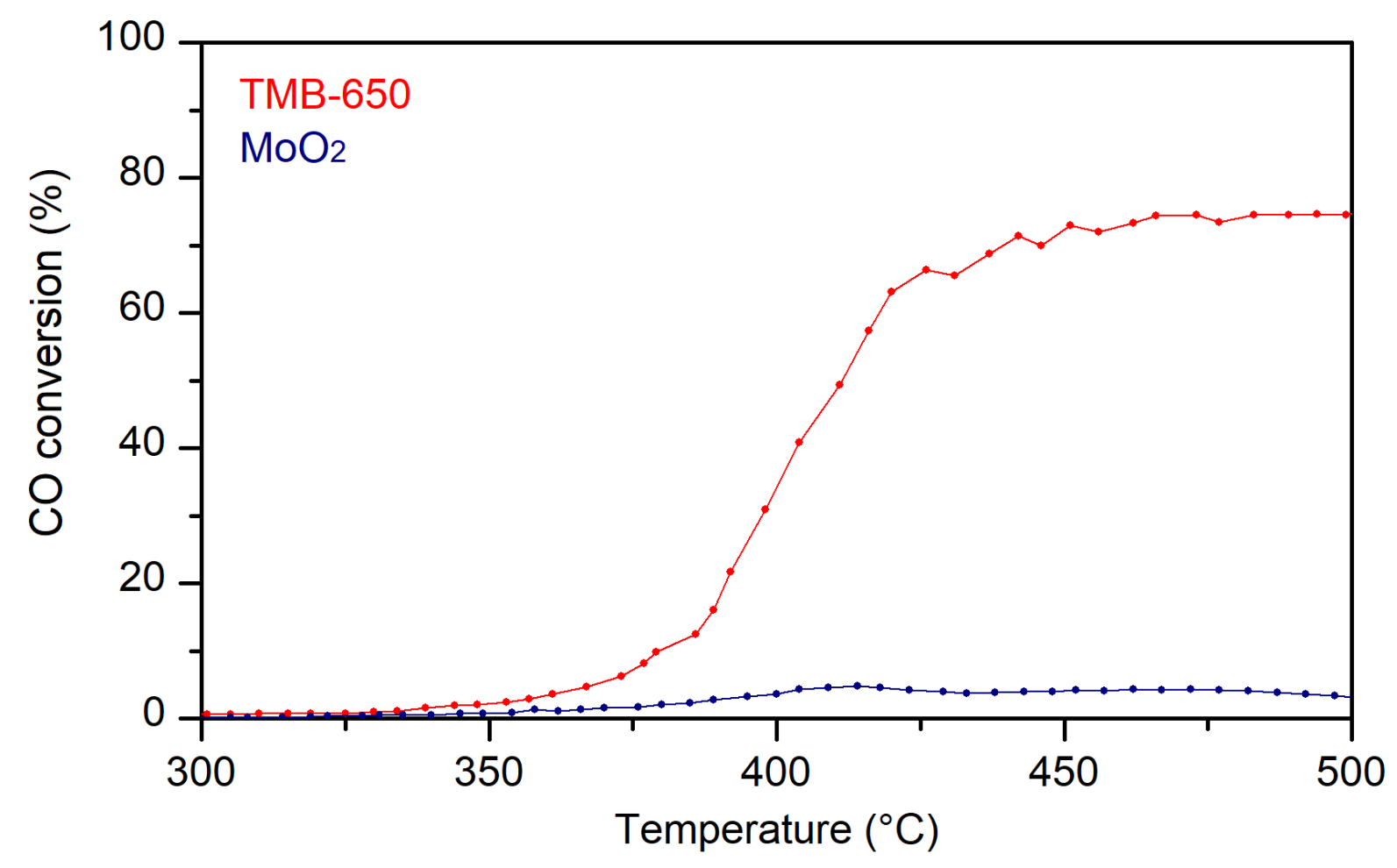

Figure S15. Catalytic performances for the WGSR: Light off curves of $\mathrm{MoO}_{2}$ compared with TMB-650. 